\title{
Positively reinforcing brain shock as a CS in the acquisition and extinction of a shuttle box avoidance response ${ }^{1,2}$
}

\author{
ROBERT M. STUTZ AND DAVID ASDOURIAN
}

WAYNE STATE UNIVERSITY

\begin{abstract}
It was predicted that animals receiving positively reinforcing electrical stimulation of the brain as a conditioned stimulus for a shuttle box avoidance response would extinguish faster than animals receiving a neutral peripheral stimulus as a CS. The two groups did not differ in terms of acquisition or extinction.
\end{abstract}

\section{Problem}

Recent experiments by Mogenson \& Morrison (1962) and Mogenson (1964) have shown that rats receiving positively rewarding electrical stimulation of the brain require more trials to reach a criterion of acquisition in a shuttle box avoidance task than animals receiving a neutral peripheral CS. Such an effect may be due to any of a number of factors: (1) The rewarding brain shock may interfere with the consolidation of the memory trace (Olds \& Olds, 1961). (2) The positively reinforcing brain shock may cause conflict. That is, since the stimulus is rewarding, animals may hesitate to make a response which terminates the CS. (3) The brain shock may reinforce incompatible responses. (4) The brain shock may attenuate the fear which has been hypothesized by Mowrer (1947) to motivate the avoidance response.

Any of these effects would tend to keep animals in the presence of a CS for longer periods of time than would a neutral CS. According to the laws of classical conditioning, keeping an aimal in the presence of a CS without primary reinforcement, i.e., foot shock, should result in faster extinction of the fear and, hence, the avoidance response (Delude \& Carlson, 1964). This study was designed to test the prediction that animals receiving positively reinforcing brain shock as a CS during avoidance learning would extinguish faster than animals receiving a peripheral neutral stimulus.

\section{Method}

The Ss were 20 male albino rats of the SpragueDawley strain, about 90 days old at the time of surgery. Bi-polar stimulating electrodes were implanted in the septal region and one week allowed for recovery. The animals were housed in individual cages with food and water available at all times.

All Ss were tested for self-stimulation in a modified Skinner box. Depression of a bar delivered a $60 \mathrm{cps}$ brain shock that could be varied from 0 to $200 \mu$ a. A Hunter Interval Timer in the circuit prevented an animal from receiving more than $.4 \mathrm{sec}$. shock for any given press. However, if the animal released the bar sooner than .4 sec., the shock was immediately terminated. Current was adjusted so as to maintain stable bar pressing rates without producing motor effects or convulsions (between 50-65 $\mu$ a for all animals).

The avoidance apparatus consisted of a shuttle box (28 $\times 11-1 / 2 \times 17$ in) with a floor constructed of $1 / 8$ in brass rods placed about $1 / 2$ in apart. Illumination was provided by two 25 watt bulbs mounted on the two sides of the apparatus. The box was divided into two equal sides by a barrier 2 in high. Su spended from the ceiling was a flexible electrode lead which could be plugged into the animal's electrode. The shock circuit was a high-voltage high-resistance circuit which permitted foot shock to be delivered up to a maximum of $5 \mathrm{ma}$. The brain shock (CS) circuit was essentially the same as that employed in the Skinner box except that it was automatically pulsed .4 sec. on, .96 sec. off. A Heath Kit audio oscillater provided a $900 \mathrm{cps}$ tone as a CS for Group II. The tone was also pulsed $.4 \mathrm{sec}$. on, $.96 \mathrm{sec}$. off. The beginning of each trial was initiated by the experimenter and terminated following a shuttling response by the animal. Latencies were recorded by a Standard Electric Timer accurate to $.1 \mathrm{sec}$.

The first 10 animals to self-stimulate (more than 100 responses in three consecutive $10 \mathrm{~min}$. sessions) were placed in Group I and received brain shock as a CS for avoidance. The remaining 10 animals were placed in Group II and received a pulsing tone as the CS.

Training in the shuttle box began with a $10 \mathrm{~min}$. familiarization period followed by a test for avoidance of the CS. The CS (tone or brain shock) began pulsing and the animal could terminate the stimulus bycrossing the barrier. The animal was required to remain in the presence of the CS for three consecutive 30-sec. bouts without making any attempt to terminate the stimulus. All animals met this test. Avoidance training was begun 5 min. later.

The avoidance conditioning procedure consisted of a CS-US interval of $5 \mathrm{sec}$. An escape response was followed by termination of both CS and US. The level of foot shock was about .7 ma, but was varied to maintain a constant behavioral effect, i.e., clear aversion without severe disruption of behavior. An avoidance response resulted in immediate termination of the CS. Intertrial intervals varied between $30 \mathrm{sec}$. and $1 \mathrm{~min}$. with a mean of $45 \mathrm{sec}$. The criterion of acquisition was set at 9 out of 10 avoidance responses (latency less than $5 \mathrm{sec}$.). Fol- 
TABLE I

\section{MEANS AND MEDIANS FOR BOTH GROUPS FOR NUMBER OF TRIALS TO ACQUISITION AND NUMBER OF EXTINCTION TRIALS}

\begin{tabular}{lllll} 
& \multicolumn{2}{c}{$\begin{array}{c}\text { No. of trials to } \\
\text { acquisition }\end{array}$} & \multicolumn{2}{c}{$\begin{array}{c}\text { No. of extinction } \\
\text { responses }\end{array}$} \\
\cline { 2 - 5 } & Mean & Median & Mean & Median \\
Group 1 & 32.8 & 31.0 & 33.6 & 24.5 \\
Group |1 & 35.7 & 33.0 & 28.6 & 21.5
\end{tabular}

lowing acquisition, extinction was immediately begun and the animals never received foot shock again. If an animal failed to respond within 5 sec., the CS remained on for another $5 \mathrm{sec}$. and then was terminated by the experimenter. Three out of five trials with a latency of more than $5 \mathrm{sec}$. was set as the criterion of extinction. Training and extinction occurred in one session.

Following extinction, all animals of Group I were again tested for self-stimulation in the Skinner box. All Ss stimulated at pre-avoidance rates within two sessions. All animals were sacrificed and perfused with $10 \%$ formalin. Brains were imbedded in celloidin, sectioned at 50 microns, and stained with cresylviolet. All electrodes were found to be either in the area of the diagonal band of broca or in the medial and lateral septal nuclei.

\section{Hesults}

Mean number of trials to acquisition and number extinction responses are shown in Table 1. There were no significant differences between the groups for either measure ( $t=-.51$ and +.51 respectively).

\section{Discussion}

The results obtained in this study do not support the prediction that positively reinforcing brain stimulation will attenuate the acquisition of or facilitate the extinction of a shuttle box avoidance habit. The acquisition data is contradictory to the results reported by Mogenson \& Morrison (1962) and Mogenson (1964). Although there were some differences between the earlier Mogenson studies and the present one, i.e., CS-US interval, locus of stimulation, and mode of CS termination on early trials, these differences would be expected to result in between-study acquisition differences rather than in differences between groups within a particular study.

With primary negative reinforcement (foot shock) absent during extinction, one might have expected that the previously rewarding stimulus would have lost its fear-provoking properties faster than would the previously neutral tone and, therefore, result in faster extinction for Group I. The explanation of the failure of this to occur is not immediately apparent. Kopa, Szabo, \& Graystyan (1962) have shown that noncontingent electrical stimulation of the same thalamic point with identical stimulus parameters in cats results in increased fear-like behavior in a "dangerous compartment" and increased relaxation in a "safe compartment." Such an effect, if at all typical of electrical stimulation of other forebrain structures (in the present experiment, the septal region), would, at least in part, contribute to the results obtained in the present experiment by maintaining a high level of fear.

\section{References}

Delude, L. A., \& Carlson, N. J. A test of the conservation of anxiety and partial irreversibility hypotheses. Canad. $J$. Psychol., 1964, 18, 15-22.

Kopa, J., Szabo, I., \& Grastyan, E. A dual behavioral effect from stimulating the same thalamic point with identical stimulus parameters in different conditioned reflex situations. Acta Physiol. Acad. Sci., Hung., October, 1962.

Mogenson, G. J. Avoidance responses to rewarding brain stimulation: replication and extension. J. comp. physiol. Psychol., $1964,58,465-467$.

Mogenson, G. J., \& Morrison, M. J. Avoidance responses to reward stimulation of the brain. J. comp. physiol. Psychol., 1962, 55, 691-694.

Mowrer, $\mathbf{O}$. H. On the dual nature of learning: a reinterpretation of "conditioning" and "problem-solving." Harv. educ. Rev., 1947, 17, 102-148.

Olds, M. E., \& Olds, J. Emotional and associative mechanisms in the rat brain. J. comp. physiol. Psychol., 1961, 54, 120-126.

\section{Notes}

1. This research is based upon a thesis submitted by the senior author in partial fulfillment of the requirements for the degree of Master of Arts at Wayne State University.

2. Supported in part by grant MH 06130 from U. S. Public Health Service to Dr. David Asdourian and by funds from the Psychology Department, Wayne State University. 